\title{
HUNGER MARKETING UM NOVO CAMINHO PARA AS EMPRESAS DE SMARTPHONES, OU NÃO? O CASO XIAOMI
}

\section{HUNGER MARKETING A NEW PATH FOR THE SMARTPHONE BUSINESS, OR NOT? THE XIAOMI CASE}

\author{
Luana Chen Chih Jun ${ }^{1}$, Henrique Nishimoto ${ }^{2}$, Natália Correia Abreu ${ }^{3}$, Vivian Siqueira ${ }^{4}$, Luciano \\ Augusto Toledo 5 \\ ${ }^{1}$ Universidade presbiteriana Mackenzie - São Paulo - SP - Brasil \\ luanachen@gmail.com \\ ${ }^{2}$ Universidade presbiteriana Mackenzie - São Paulo - SP - Brasil \\ yudi.nishimoto@gmail.com \\ ${ }^{3}$ Universidade presbiteriana Mackenzie - São Paulo - SP - Brasil \\ Natália@gmail.com \\ ${ }^{4}$ Universidade presbiteriana Mackenzie - São Paulo - SP - Brasil \\ vivian.damaceno10@gmail.com \\ ${ }^{5}$ Universidade presbiteriana Mackenzie - São Paulo - SP - Brasil \\ luciano.toledo@mackenzie.br
}

\begin{abstract}
Resumo
O presente estudo se apresenta sobre a forma de pesquisa exploratória qualitativa. É posteriormente complementado com o uso de um estudo de caso no âmbito do Hunger Marketing. Para tanto foi realizada uma pesquisa por meio de aplicação de questionários semiestruturados objetivando entender a priori: como o Hunger Marketing está a serviço de empresas manufaturadoras de telefonia móvel. Finalmente conclui-se que o termo Hunger Marketing não é totalmente novo, visto que ele também se baseia na busca por experiências e nas necessidades dos consumidores. A principal diferença dele para o marketing experiencial é que ele cria o desejo, enquanto o marketing experiencial busca atender esse desejo. Apesar disso, ambos têm como principal objetivo satisfazer o cliente e garantir a geração de emoções e satisfação. Também se nota que a utilização desse marketing pode não gerar os resultados esperados, visto que a empresa está lidando com uma variável não controlável que é o próprio consumidor. Trabalhar as necessidades pode ser algo vantajoso e competitivo, mas deve-se tomar cuidado com relação as expectativas, já que para alguns consumidores esperar pelo produto pode ser prazeroso $e$ interessante, enquanto que para outros pode gerar frustações e tormentos algo que limite a ação de compra.
\end{abstract}

Palavras-chave: hunger marketing; smartphones; Mercado global; China

\section{Introdução}

Vislumbra-se contemporaneamente o aumento da competitividade empresarial e o desdobramento da revolução global (MORAES; TOLEDO, 2013; FROW et al., 2015; KOTLER; KELLER, 2009). Por um lado, tem-se o fenômeno da globalização, e por outro, desenrola-se a 
revolução tecnológica capitaneada pelo uso da internet, da WEB 2.0 e dos negócios empresariais "climatizados" na computação em nuvem. Neste ambiente, técnicas como o just-in-time e a produção enxuta são apresentadas como alternativas para a superação de obstáculos que atingem a cadeia de valor das organizações. Indiscutivelmente, tais alternativas implicam alterações nos processos de trabalho, melhorando a utilização de recursos, e, consequentemente, promovendo a redução de custos (MORAES; TOLEDO, 2013; FROW et al., 2015; KOTLER; KELLER, 2009). Essas alterações pelas quais as organizações estão sujeitas no atual ambiente de negócios contemporâneo são necessárias para que o nível de competitividade organizacional se mantenha crescente e constante. Inseridas em um ambiente dinâmico e competitivo, para permanecerem competitivas, as organizações não podem depender exclusivamente da eficácia operacional (MORAES; TOLEDO, 2013; FROW et al., 2015; KOTLER; KELLER, 2009). É imperativo ser singular e apresentar diferenciação e, assim, colocar em prática mecanismos que efetivamente melhorem os processos produtivos organizacionais, e que, independentemente de resultados numéricos, devam promover um fluxo contínuo de melhorias. Assim, nesse panorama de revolução tecnológica e cultural, destaca-se a inteligência de marketing como apoio aos gestores empresariais (BROWN; EISENHARDT, 1998; HOOLEY; PIERCY; NICOULAUD, 2008; PETTIGREW; THOMAS; WHITTINGTON, 2002). Neste contexto surge o conceito de Hunger Marketing como uma possível alternativa inovadora para a realização da função essência de marketing: o estímulo a troca.

A luz do exposto anteriormente justifica-se um trabalho acadêmico que levante dados de como o Hunger Marketing contribui para o serviço de manufaturadoras de telefonia móveis.

\section{Problema de Pesquisa}

É o Hunger Marketing uma contribuição as estratégias de marketing tradicionais de manufaturadoras de telefonia móveis?

\section{Objetivo Geral}

Verificar como o Hunger Marketing contribui para as manufaturadoras de telefonia móveis?

\subsection{Objetivo Específicos}

- Estudar os conceitos balizadores de marketing;

- Estudar a evolução do marketing experiencial ao Hunger Marketing;

- Investigar o Hunger Marketing na empresa Xiaomi 


\section{Procedimentos Metodológicos}

Ao término da revisão de literatura que compete ao tema, descrevem-se os procedimentos metodológicos utilizados para a realização do presente estudo, bem como sua natureza e métodos. Esse estudo é de natureza qualitativa, uma vez que seus resultados não podem ser comprovados numérica ou estatisticamente, mas sim na forma de experimentação empírica, a partir de análise feita de forma detalhada, abrangente, consistente e coerente, com argumentação lógica das ideias (MICHEL, 2009). A metodologia qualitativa abrange a análise e interpretação de aspectos mais profundos, descrevendo a complexidade do comportamento humano, fornecendo uma análise mais detalhada sobre as investigações, hábitos, atitudes e tendências de comportamento (LAKATOS, MARCONI, 2011).

Este estudo tem por objetivo estudar o Hunger Marketing, técnica utilizada pela empresa Xiaomi. Como método de coleta de dados utilizou-se a pesquisa em depoimentos da equipe de marketing da Xiaomi no Brasil. Os dados foram coletados a partir de entrevistas semiestruturadas com um total de 6 funcionários da empresa, sendo três formados em Administração, um em Publicidade e Propaganda e outros dois em Economia. Dentre os entrevistados, dois deles são chineses que vieram para o Brasil quando a empresa decidiu iniciar operações aqui, e um deles atua na Xiaomi há 4 anos e o outro há 3 anos. Os demais começaram a trabalhar quando as operações começaram aqui, há menos de um ano. A técnica de entrevistas semiestruturadas foi escolhida pelo seu caráter de profundidade, o qual "o entrevistador tem liberdade para desenvolver cada situação em qualquer direção que considere adequada" (LAKATOS; MARCONI, 2011). De acordo com os autores, o entrevistador pode requerer mais esclarecimentos sobre determinado aspecto da entrevista, possibilitando a aquisição de mais dados que não se encontram em fontes secundárias e são relevantes, mas não previamente inseridos no roteiro da entrevista.

Assim o papel da metodologia da pesquisa é guiar o processo da pesquisa por meio de um [1] sistema de procedimentos. Um método é um conjunto de processos pelos quais se torna possível estudarem uma determinada realidade (COOPER; SCHINDLER, 2003; YIN, 2013). Caracteriza-se, ainda, pela escolha de procedimentos sistemáticos para descrição e explicação de uma determinada situação sob estudo. Para o atual estudo, conjecturou-se utilizar o método do estudo de caso em função do seu caráter qualitativo. O estudo de caso é adotado quando se colocam questões do tipo "como" e "por quê", (GOWER, 2012) quando o pesquisador tem pouco controle sobre os acontecimentos e quando no foco se encontram fenômenos contemporâneos inseridos em algum contexto da vida real (DIÓGENES, 2005; SANTO, 1992). Ainda em conformidade ao autor, pelo fator de não se aplicar o conceito corriqueiro de amostra, o presente trabalho utiliza como premissa, a Unidade de Análise (GOWER, 2012; YIN, 2012). 
Assim sendo, a Unidade de Análise deste estudo resume-se nas atividades da empresa investigada, relacionadas às atividades da Inteligência de Marketing. Para essa pesquisa, utilizou-se o estudo de caso único. A empresa objeto será a XIAOMI. Neste contexto, as informações coletadas serão analisadas de acordo com o padrão combinado de Yin (2013), no qual se faz a comparação de padrões com base empírica aos previstos na teoria preconizada. Ainda, como fonte de aplicação dos questionários serão entrevistados: analista de marketing, analista de mídias sociais, gerente de marketing, gerente de tecnologia e um dos sócios proprietários da empresa. Para o mesmo, foi selecionado como forma de coleta de dados o questionário semiestruturado, pela sua característica fundamental de permitir ao entrevistador extrair o máximo de informação das entrelinhas das respostas obtidas. Não obstante, aplicou-se a triangulação como método de coleta de dados por múltiplas fontes. Assim, foram consultados os canais eletrônicos que de uma forma ou outra estavam relacionados a empresa estudada, como? Blog da empresa, o canal do Youtube, Facebook e Twitter. Com base na teoria preconizada por Yin (2013), o tratamento dos dados será a adequação ao padrão, modelo no qual os dados observados são comparados com a teoria disponível e estudada. Não obstante, a utilização de um protocolo do estudo de caso é fundamental para maior credibilidade científica ao trabalho (TOLEDO; SHIRAISHI, 2009). Assim, tem-se a utilização do mesmo como uma sequência a ser seguida pelos pesquisadores, contendo um resumo dos conceitos metodológicos do trabalho e as questões pesquisadas.

\section{Referencial Teórico}

\subsection{Síntese conceitual acerca de Marketing}

Marketing são ações operadas por organizações e também um procedimento social, existindo tanto nos níveis micro como macro. Por esse motivo, pode-se conceber marketing sob um duplo enfoque (FERRELL; HARTLINE, 2012; HOOLEY; SAUNDERS; PIERCY, 2001; KOTLER; KARTAJAYA; SETIAWAN, 2011; LAMBIN, 2002; TOLEDO; PERROTTA; PETRAGLIA, 2008). No primeiro examinam-se os consumidores e as organizações que os atendem; no segundo adota-se uma visão ampla do sistema completo de produção e distribuição em que a organização opera. Marketing deseja compreender, delinear, desenvolver e entregar bens e serviços que os consumidores desejam e necessitam; consiste em proporcionar aos consumidores produtos, no tempo certo, no local certo e no preço que estão dispostos a pagar. No âmago do conceito, sobressai o objeto ou razão de ser do marketing: a troca. Por outro lado, ao envolver-se no procedimento de troca, marketing propicia quatro tipos de utilidade: forma, tempo, lugar e posse. Em uma economia avançada e dinâmica, a prática do marketing é mais complexa, porque produtores e consumidores estão separados de várias maneiras. As discrepâncias de quantidade e de 
sortimento dificultam ainda mais o estabelecimento de trocas eficientes entre produtores e consumidores (FERRELL; HARTLINE, 2012; HOOLEY; SAUNDERS; PIERCY, 2001; KOTLER; KARTAJAYA; SETIAWAN, 2011; LAMBIN, 2002; TOLEDO; PERROTTA; PETRAGLIA, 2008). Em tal contexto, cada produtor especializa-se em fabricar e vender grandes quantidades de um sortimento limitado de bens e serviços, mas cada consumidor deseja apenas pequenas quantidades de um sortimento amplo desses bens e serviços.

As funções universais de marketing, tanto as que se referem à análise e ao delineamento do mercado como as que compreendem o procedimento decisório, ajudam na tarefa de gerenciamento, mas é necessário que se convertam em algo. As formas como essas funções são operacionalizadas e as responsabilidades daqueles que as desempenharão podem diferir entre países, sistemas econômicos e entre organizações. Comumente, a troca envolve compra e venda e todo o procedimento de informação, comunicação, negociação, distribuição e entrega (PIGGOTT, 1996). Uma estratégia pode ser concebida como sequencia temporal de deliberações, ou, alternativamente, como um procedimento que envolve um conjunto de ações voltadas para mover uma organização em direção ao cumprimento de suas metas de curto prazo e seus escopos de longo prazo.

As estratégias encontram-se presentes em todas as organizações, tanto as mais simples como as maiores e mais complexas, podendo variar em relação ao grau de formalismo com que são formuladas. Em algumas organizações, em especial naquelas que operam em ambientes que mudam rapidamente, ou em organizações de pequeno porte, as estratégias não são definidas ou "planejadas" na concepção formal do termo. Além do grau de formalismo, as estratégias podem ser consideradas em relação ao fato de serem deliberadas ou emergentes (PIGGOTT, 1996). Na estratégia deliberada, os gerentes planejam seguir um determinado curso de ação predefinido e intencional. A estratégia emergente significa que ela não é essencialmente planejada ou intencional, mas o resultado de padrões e consistências observadas no passado, mediante um procedimento de tentativa e erro. Esses dois últimos conceitos constituem os limites das diferentes combinações que formam a base de uma tipologia que caracteriza os procedimentos de formulação de estratégias. A formulação de estratégia, concebida como o procedimento de planejar as estratégias, ou, no sentido mais amplo, o procedimento de planejamento estratégico, pode ser desdobrado em três níveis corporativo, empresarial ou da unidade de negócio e funcional (BAINES; FILL; PAGE, 2013; KOTLER; KELLER, 2009).

Em organizações de porte médio com uma única unidade de negócio, o planejamento estratégico de marketing e o planejamento operacional de marketing podem ser arquitetados como um procedimento único, e, em organizações menores, o procedimento de planejamento incorpora os três níveis simultaneamente. Quando se trata de estratégicas no âmbito corporativo, as deliberações são tomadas nos escalões mais altos da organização, conquanto as pessoas que se encontrem nesse 
nível possam receber informações de gestores de níveis mais baixos (FERRELL; HARTLINE, 2012; HOOLEY; SAUNDERS; PIERCY, 2001; KOTLER; KARTAJAYA; SETIAWAN, 2011; LAMBIN, 2002; TOLEDO; PERROTTA; PETRAGLIA, 2008). Se uma determinada organização contar apenas com uma única unidade de negócios, as deliberações do primeiro e segundo níveis são tomadas pelas mesmas pessoas. Em organizações com múltiplos negócios, as deliberações no nível da unidade de negócios são tomadas pelos executivos de maior nível dentro da unidade; no nível da área funcional, as deliberações são tomadas pelos concernentes gerentes.

Uma questão relevante, relacionada com os aspectos organizacionais do plano de marketing trata-se de a quem atribuir a responsabilidade pela redação do plano de marketing. Em algumas organizações, a responsabilidade pode caber ao gerente de marketing, ao gerente de marca ou ao gerente de produto; em outras, os planos são elaborados por um comitê. Existem ainda aquelas que contratam consultores de marketing para redigir o plano. Teoricamente seria responsabilidade pelo planejamento de marketing repousa no nível do vice-presidente de marketing ou do diretor de marketing, na maior parte das organizações). Ressalta-se, ainda, que a aprovação final do plano de marketing cabe ao $\mathrm{CEO}$ ou ao presidente, conquanto muitas organizações recorram a comitês executivos, que meditem e filtrem os planos de marketing antes de submetê-los ao dirigente que o aprovará (FERRELL; HARTLINE, 2012; HOOLEY; SAUNDERS; PIERCY, 2001; KOTLER; KARTAJAYA; SETIAWAN, 2011; LAMBIN, 2002; TOLEDO; PERROTTA; PETRAGLIA, 2008).

Indubitavelmente o marketing desempenha componente fundamental na formulação e implantação da estratégia, isso porque a administração estratégica tem que lidar permanentemente como um ambiente em constante mudança, no qual se sobressaem duas entidades e forças: o mercado e a concorrência. Isso obriga as organizações, em ambientes competitivos, caracterizados por oferta maior que a demanda, a pautarem suas ações em uma filosofia de orientação para o mercado. A relevância e pertinência do marketing em organizações orientadas para o mercado, que mantêm um duplo foco entre mercado e concorrência, podem ser destacadas mediante três elementos ou papéis que constituem o ponto central de seu procedimento estratégico (KUMAR, 2013; TOLEDO, 1994; TOLEDO; PERROTTA; PETRAGLIA, 2008).

Nesse contexto, um primeiro papel ou tarefa de marketing é a identificação das características, perfis, exigências e demandas dos clientes e a comunicação e disseminação eficaz das informações para a organização como um todo. $\mathrm{O}$ segundo é determinar o posicionamento competitivo, de modo a ajustar os recursos, capacidades e escopos da organização às necessidades diversificadas dos clientes. Essa tarefa implica reconhecer que os mercados são heterogêneos; cabe, portanto, à organização identificar os segmentos que os compõem, ajuizar o grau de atratividade de cada um deles e, simultaneamente, analisar a condição competitiva para atendê-la (FERRELL; 
HARTLINE, 2012; HOOLEY; SAUNDERS; PIERCY, 2001; KOTLER; KARTAJAYA; SETIAWAN, 2011; LAMBIN, 2002; TOLEDO; PERROTTA; PETRAGLIA, 2008). Essa análise determinará a estratégia de segmentação que a organização irá adotar, em busca do atendimento de seus escopos de crescimento e rentabilidade. O terceiro papel revelador da relevância e pertinência do marketing no procedimento competitivo prende-se à tarefa de implantação da estratégia, o que significa alinhar os recursos da organização para planejar e executar a entrega de valor e consequente satisfação do cliente.

O marketing contribui na coordenação dos esforços que visam a garantir o contentamento do cliente e a mantê-lo colocando em relevo a pertinência do marketing na ação e arquitetura do plano estratégico. Um dirigente de organização, ainda que avesso a qualquer ideia de planejamento tenha que lidar sucessivamente com três tipos de questões (FERRELL; HARTLINE, 2012; HOOLEY; SAUNDERS; PIERCY, 2001; KOTLER; KARTAJAYA; SETIAWAN, 2011; LAMBIN, 2002; TOLEDO; PERROTTA; PETRAGLIA, 2008): Definição e avaliação dos investimentos na capacidade produtiva, necessários para responder à evolução da demanda ou para desenvolver novos produtos e/ou mercados, ou seja, para atender os escopos corporativos de crescimento e de rentabilidade; Estabelecimento do programa de produção necessário para atender às previsões de pedidos, tendo em conta que esses pedidos e encomendas são uma variável dependente da sazonalidade e dos ciclos da demanda (incontrolável) e das ações decorrentes dos esforços de marketing da organização (controlável); Os recursos financeiros necessários para fazer frente aos compromissos estimados no procedimento de previsão de despesas e receitas.

Os problemas apontados são inerentes ao procedimento gerencial de qualquer organização, e sua solução tem por ponto de partida as previsões de vendas nos prazos curto médio e longo (FERRELL; HARTLINE, 2012; HOOLEY; SAUNDERS; PIERCY, 2001; KOTLER; KARTAJAYA; SETIAWAN, 2011; LAMBIN, 2002; TOLEDO; PERROTTA; PETRAGLIA, 2008).

O procedimento de marketing e, por conseguinte, o procedimento de planejamento formal de marketing também ocorre em dois níveis (BRITO; TOLEDO; TOLEDO, 2009) estratégico e operacional. O procedimento de planejamento estratégico de marketing tem por escopo exprimir, de um modo claro e sistemático, as alternativas escolhidas pela organização, tendo em vista a assegurar seu crescimento no médio e longo prazo (LAMBIN, 2002). Em seguida, as alternativas serão convertidas em deliberações e programas de ação. A abordagem de marketing, no contexto do planejamento estratégico de marketing, articula-se em torno das seguintes questões fundamentais, cujas respostas constituirão a espinha dorsal do procedimento de planejamento e, eventualmente, de um plano estratégico de marketing (FERRELL; HARTLINE, 2012; HOOLEY; SAUNDERS; 
PIERCY, 2001; KOTLER; KARTAJAYA; SETIAWAN, 2011; LAMBIN, 2002; TOLEDO; PERROTTA; PETRAGLIA, 2008):

- Definição do mercado de referência (mercado a ser considerado) e estabelecimento da missão estratégica da organização nesse mercado;

- Identificação da diversidade do binômio produto-mercado no mercado no mercado de referência e definição dos posicionamentos suscetíveis de serem adotados;

- Avaliação da atratividade intrínseca dos binômios produto-mercado e identificação das situações favoráveis e desfavoráveis do ambiente;

- Para cada binômio produto-mercado levantar os trunfos da organização, bem como suas forças e fraquezas e o tipo de vantagem competitiva que ela a organização pode desenvolver;

- Estabelecimento de uma estratégia de cobertura e de ampliação a ser adotada e do nível de ambição (escopos) estratégica, em termos de crescimento e lucratividade;

- Traduzir os escopos estratégicos e convertê-los em um programa de ação que considere as variáveis que compõem o procedimento de marketing no nível operacional: produto, preço, promoção, praça.

\subsection{Processo decisório}

O processo decisório de um cliente começa quando ele reconhece que um problema deve ser resolvido ou que uma necessidade precisa ser satisfeita (SHETH; MITTAL; NEWMAN, 2001). Um problema do cliente é qualquer estado de falta, privação ou desconforto que uma pessoa sinta, seja ele físico ou psicológico. O reconhecimento do problema é quando o cliente percebe que precisa comprar algo para que seu estado normal de conforto volte (SHETH; MITTAL; NEWMAN, 2001; FIFIELD, 2012; KOTLER; KELLER, 2009).

O reconhecimento do problema pode ocorrer em virtude de dois tipos de estímulos: os internos e os externos. Os internos são causados por fatores físicos ou psicológicos que geram algum desconforto no cliente, como a sensação de fome ou sonolência. Por outro lado, os fatores externos são itens do mercado que fazem com que o cliente perceba o problema, como uma propaganda de comida ou o cheiro de um perfume (SOLOMON, 2011).

Após a identificação do problema, o cliente busca informações para resolver a necessidade apresentada. Ele cria, em sua mente, um conjunto considerado de marcas, ou seja, as marcas lembradas por ele e que podem atender sua necessidade. A partir disso, ele fará uma análise das marcas que ali estão presentes de acordo com alguns elementos julgados como essenciais para que a escolha mais correta seja feita (SHETH; MITTAL; NEWMAN, 2001; FIFIELD, 2012; KOTLER; KELLER, 2009). 
A primeira atitude tomada pelo cliente é analisar as informações fornecidas pelas fontes empresariais, que são aquelas que vem da própria empresa que fabrica o produto e que visa sempre fornecer informações favoráveis, como sites, lojas e propagandas (LIMEIRA, 2009). Além dessas fontes, há também as informações fornecidas pelas fontes não empresariais, que não estão no alcance das empresas, como amigos e familiares, experiências anteriores e especialistas na área (SHETH; MITTAL; NEWMAN, 2001; FIFIELD, 2012; KOTLER; KELLER, 2009).

Além de analisar as fontes das informações, o cliente também determina qual será sua estratégia de busca. Caso seu problema já tenha acontecido anteriormente e a solução encontrada foi considerada como uma boa escolha pelo cliente, ele irá utilizar a resolução rotineira de problemas, em que ele não precisará investir muito tempo na decisão (SOLOMON, 2011). Entretanto, se o problema apresentado demanda uma busca mais extensiva e a deliberação mais prolongada, a melhor estratégia é resolução estendida de problemas, que serve para compras nunca feitas e que envolvam riscos maiores (SHETH; MITTAL; NEWMAN, 2001). Por último, há a resolução limitada de problemas, que é usada quando o cliente investirá um tempo e energia limitados na busca por informações, já que existe certa familiaridade com o problema reconhecido (SHETH; MITTAL; NEWMAN, 2001).

Outro fator importante na busca pelas informações é a quantidade de busca, ou seja, quais são as determinantes para que o cliente escolha pelo produto A e não pelo B. Fatores como risco percebido, importância percebida, familiaridade, tempo disponível e natureza funcional e expressiva são de extrema importância na hora da tomada de decisão (SOLOMON, 2011).

Com o problema reconhecido e a busca pelas informações feitas, o cliente agora precisa fazer uma avaliação das alternativas, para identificar, entre todas as opções apresentadas a ele, qual melhor se encaixa na solução do seu problema (SOLOMON, 2011). Os processos e passos necessários para se fazer essa escolha são chamados de "modelos de escolha", e são divididos em duas amplas categorias: os compensatórios e os não compensatórios (SHETH; MITTAL; NEWMAN, 2001; FIFIELD, 2012; KOTLER; KELLER, 2009).

No modelo compensatório, o cliente faz sua escolha considerando todos os atributos de um produto, ou os benefícios de um serviço, e compensa mentalmente os pontos fracos em um ou mais atributos fortes, ou seja, uma falha em um benefício pode ser compensada pela boa classificação de um outro atributo (LIMEIRA, 2009). No modelo não compensatório, existem quatro subgrupos mais úteis e importantes. O modelo conjuntivo, em que o cliente determina limites mínimos aceitáveis na hora de decidir qual produto comprar; o modelo disjuntivo, que o cliente compensa a ausência de um atributo por outro; o modelo lexicográfico, em que o cliente determina a ordem de importância dos atributos e faz sua escolha a partir daquele que apresentar maior nível e o modelo de eliminação por aspectos, que o cliente classifica os atributos por ordem de importância e define 
valores mínimos de eliminação (SHETH; MITTAL; NEWMAN, 2001; FIFIELD, 2012; KOTLER; KELLER, 2009).

Independente do modelo utilizado, os clientes nunca podem e nunca irão avaliar todas as alternativas exaustivamente, o que os leva a fazer escolhas pouco sensatas (SOLOMON, 2011). O cliente está condicionado a aceitar a escolha que lhe parecer mais satisfatória dentre todas as alternativas apresentadas, mesmo sabendo que ela pode haver um produto melhor na loja ao lado (LIMEIRA, 2009).

Depois de identificar o problema, buscar as informações e analisar as alternativas, o cliente enfim pode comprar o produto que ele elegeu como melhor opção para resolver sua necessidade (LIMEIRA, 2009). O processo da compra é dividido entre três etapas: (1) identificação da escolha, (2) intenção de compra e (3) implementação da compra, porém, nem sempre essas etapas acontecem de maneira previsível, o que pode gerar demora na implantação ou um desvio com relação a escolha identificada (SHETH; MITTAL; NEWMAN, 2001; FIFIELD, 2012; KOTLER; KELLER, 2009).. Vários fatores são responsáveis por essas alterações, tais como falta de tempo, recursos escassos, pouca informação, alteração administrativa na empresa, o surgimento de melhores alternativas ou a necessidade tornar-se passageira (LIMEIRA, 2009).

Com a compra realizada, o último estágio do processo decisório é a avaliação pós-compra, que vai analisar a experiência do cliente com seu produto ou serviço escolhido. Ele é dividido em quatro etapas: (1) confirmação da decisão, (2) avaliação da experiência, (3) satisfação/insatisfação e (4) resposta futura (abandono, reclamação ou lealdade) (SOLOMON, 2011).

Com a compra realizada, o cliente sente uma grande necessidade de confirmar a sensatez da mesma, mostrando as vantagens e as boas características do produto para os amigos, evitando que haja uma dissonância cognitiva (SHETH; MITTAL; NEWMAN, 2001; FIFIELD, 2012; KOTLER; KELLER, 2009). Após a compra, o cliente efetivamente consume seu produto ou serviço recém adquirido. Com esse consumo os clientes terão uma opinião formada a respeito dele, e poderão desenvolver um resultado de uso. Esse resultado apresentará se os clientes ficaram satisfeitos ou insatisfeitos com a compra realizada e por que eles apresentaram esses resultados (SHETH; MITTAL; NEWMAN, 2001; FIFIELD, 2012; KOTLER; KELLER, 2009). Após a experiência de estar satisfeito ou não, os clientes podem desenvolver três respostas: abandonar o produto e nunca mais comprar da mesma marca, reclamar sobre o produto e só depois decidir se continuarão ou não a comprar daquela marca e desenvolver uma lealdade, que não necessariamente significa comprar apenas daquela marca, mas realizar a recompra (SOLOMON, 2011). 


\subsection{Do marketing tradicional ao marketing experiencial}

O marketing é, atualmente, um dos conceitos mais importantes no mundo empresarial. No entanto, trata-se de uma área com uma complexidade enorme, devido à sua enorme abrangência e à sua ligação direta com os consumidores que têm vindo a alterar os seus comportamentos, pelo que ao longo dos anos a sua definição tem sofrido várias alterações (PRATAS, 2013).

O marketing tradicional representa um conjunto de variáveis controláveis de marketing que as empresas utilizam para conseguirem respostas sobre seu mercado-alvo, ou seja, a empresa define sua estratégia de mercado e como irá se posicionar em relação à concorrência. (KOTLER; ARMSTRONG, 2008).

O consumidor não faz parte do mix de maketing, pois na realidade é o objetivo, o alvo dos esforços de marketing. Desta forma é importante que os profissionais da área procurem focalizar-se nas variáveis de marketing de forma que estas sejam dirigidas aos principais interessados, os consumidores, de forma assertiva para irem de encontro aos seus desejos e necessidades. O produto é desenvolvido para satisfazer determinado público-alvo e é preciso um ponto (canal de distribuição), um local para que o público possa adquiri-lo. A promoção é utilizada para informar o público-alvo sobre a disponibilidade do produto e o preço que é estabelecido após computar o custo de produção, margem de lucro e o quanto o consumidor está disposto a gastar (MCCARTHY; BROGOVICZ, 1982).

Portanto, o marketing tradicional, cujo principal foco eram os atributos físicos dos produtos e a sua qualidade, deixou de fazer sentido com o surgimento da Economia das Experiências, pois nesta nova era, os consumidores procuram por memórias efetivas, por sensações, por simbolismo, por aquilo que lhe permita criar uma experiência pessoal única e memorável (PINE; GILMORE, 1998; SCHMITT, 2003).

O marketing deve então começar a analisar quais são as necessidades dos consumidores que não estão sendo satisfeitas e procurar que essas lacunas sejam supridas, a partir da inserção no mercado de produtos e/ou serviços que proporcionem satisfação nos consumidores. Assim, ao oferecerem o que os clientes procuram e desejam, as empresas vão-se destacando no mercado e adquirindo um melhor posicionamento. Nesta definição está referenciada uma das principais características do Marketing da atualidade: a preocupação com os consumidores. Este aspeto é considerado a base do Marketing das empresas, uma vez que o objetivo fundamental das organizações consiste na satisfação das necessidades e desejos dos consumidores (PRATAS, 2013).

O marketing experiencial surgiu com o aumento da eficiência dos mercados e da existência de uma competitividade cada vez maior entre as empresas, assim como as mudanças no comportamento de compra do consumidor trouxe a necessidade de adotarmos uma concepção de marketing mais adaptada a realidade desse novo mercado e das demandas dos consumidores 
(MORAL; ALLES, 2012). A experiência fornece mais orientação, agrega mais valor para o cliente do que a satisfação. A experiência é geralmente o que gera a satisfação do cliente e que é onde o foco deve ser (SCHMITT, 2003).

Os fatores que levaram à evolução do marketing tradicional para o marketing experiencial são (SCHMITT, 1999):

- A penetração da tecnologia da informação, determinando promover o encontro e a ligação entre a empresa e o cliente, como um meio para a criação de valor e melhoria da experiência do cliente;

- A supremacia da marca. Impulsionado pelas tecnologias de informação estará disponível a partir da informação de forma imediata, sendo a marca um meio para facilitar a experiência dos clientes;

- Prevalência de comunicações e entretenimento. Será imposta a comunicação fluida entre a empresa e fruto de uma maior orientação das organizações com o cliente final.

O uso do marketing experiencial como uma ferramenta de comunicação está crescendo rapidamente com empresas acreditando que seu uso pode proporcionar-lhes uma vantagem competitiva em comparação com a comunicação tradicional. No entanto, poucos estudos têm avaliado o seu impacto sobre os consumidores. Portanto, é necessário avaliar o impacto de um evento marketing experiencial sobre a percepção da essência da marca dos clientes, pois as empresas, de modo a ter uma vantagem competitiva, são pressionadas pelo mercado e por seus clientes, para chegar a experiências que estimulam suas emoções e sensações alvo (ARONNE; VASCONCELOS, 2009).

Assim, as empresas que desejam destacar-se em meio a tantas opções e explorar melhor o seu valor de marca com experiências positivas de consumo, gerando não somente produtos com funcionalidades que supram as necessidades dos indivíduos, mas diferentes tipos de percepções e vivências ao consumidor. No mundo em que as marcas governam, produtos não são mais pacotes de características funcionais, mas significam proporcionar e melhorar as experiências do consumidor (SCHMITT, 1999; SARGI; MATTOS, 2015);

Atualmente, a marca tem desempenhado um papel fundamental nas transações comerciais entre as empresas durante os processos de aquisição. Hoje se fala muito em Brand Equity que consiste em um conjunto de ativos e passivos ligados a uma marca, seu nome e seu símbolo, que se somam ou se subtraem do valor proporcionado por um produto ou serviço para uma empresa e/ou para os consumidores dela (FOG; BUDTZ; YAKABOYLU, 2005; GOBE, 2001; KOTLER; PFOERTSCH, 2010; MONTOYA, 2002). A marca passou a ter uma grande importância nos processos de aquisição por constituir um ativo intangível, muito difícil de ser copiado. Fica evidente que a empresa que consegue fixar e manter um nome forte na lembrança do consumidor de forma 
positiva e com isso, trabalhar a imagem da organização, estará obtendo uma vantagem competitiva frente aos demais concorrentes. Ao lado da demanda, a marca tem o poder de capacitar o produto a alcançar um preço maior, a aumentar o volume de vendas (market share) e a reter e aumentar seu uso pelos consumidores (FOG; BUDTZ; YAKABOYLU, 2005; GOBE, 2001; KOTLER; PFOERTSCH, 2010; MONTOYA, 2002).

A partir de todo este contexto, nota-se a relevância em gerar experiências cada vez mais significativas para os consumidores antes, durante ou após a compra, visto que quanto melhor a interação destes com o meio em que estão presentes maior a probabilidade de desencadear emoções (SARGI; MATTOS, 2015).

\subsection{Hunger Marketing}

O termo Hunger Marketing, ou, marketing fome em português, é um tipo de estratégia que se utiliza de conhecimentos comportamentais para redirecionar a atenção do consumidor a aquisição de novos produtos (YAN; QU, 2014).

A estratégia que sustenta o conceito de Hunger Marketing é simples de operar. O negócio traz produtos ao mercado com um preço atraente para atrair clientes potenciais, em seguida, restringe a oferta, resultando em uma escassez imaginário que pode aumentar os preços e, portanto, gerar lucros mais elevados (DRELL, 2011; SCHMITT, 1999; STONE; SATARIANO; TONESS, 2014). Não obstante o conceito de Branding é um fator que atravessa toda a operação de hunger marketing e assim a estratégia deve contar com uma marca de forte apelo. O efeito final não é apenas para aumentar os preços, mas também criar maior valor agregado para a marca, a fim de estabelecer uma imagem de marca de alto valor (SHEERAN, 2008).

Para que o Hunger Marketing tenha sucesso, é necessário criar experiências. Portanto, as empresas podem utilizar da interação da mídia social online para tornar a relação com seus consumidores mais próximas, de que modo que se sintam parte do seu processo de produção. Além disso, devem controlar o seu volume de vendas de forma que seus clientes tenham a percepção de que estão adquirindo um produto exclusivo, algo que apenas o dinheiro não pode comprar, devido a sua produção limitada (YAN; QU, 2014).

O conceito de Hunger marketing foi forjado inicialmente dentro das unidades de negócio da empresa chinesa Xiaomi. A mesma utiliza um método que trabalha na obsessão do consumidor. Através de redes sociais, a empresa utiliza o feedback de seus clientes, para ajudar no desenvolvimento de seus novos produtos. Após essa etapa, fazem uso da estratégia de estoque limitado, para cortar gastos com a manutenção de inventário. Disponibilizando, semanalmente, pequenas quantidades, que são esgotadas em poucos minutos (GUPTA; ISHNEET, 2014). Para a empresa chinesa, um de seus valores essenciais é focar em seus fãs. Portanto procura engajá-los 
com tópicos interessantes, respondendo comentários, compartilhando ideias, criando oportunidades para estreitar a relação da empresa e seus consumidores. Além disso, o seu software é atualizado semanalmente, para que seus fãs possam testar as novas funcionalidades. Assim, mantém seus clientes sempre estão esperando algo novo da empresa (SHIH; LIN; LUARN, 2014).

\section{Resultado da pesquisa}

\subsection{Contexto de mercado global de smartphones}

O mundo está vendo uma migração tecnológica acelerada tanto para as redes de celulares móveis de banda larga com velocidade, como o aumento da adoção de smartphones e outros dispositivos virtualmente conectados. Conexões de telefonia móvel serão responsáveis por quase $70 \%$ da conexão global até 2020, o que há pouco tempo representava menos de $40 \%$. O uso de smartphones já está atingindo massa crítica em países desenvolvidos, com os dispositivos agora respondendo por $60 \%$ das conexões. É o mundo em desenvolvimento, devido ao aumento de dispositivos acessíveis, fato que será o maior responsável pelo crescimento futuro, sendo que a perspectiva é que ocorra um aumento de mais 2,9 bilhões de conexões de smartphones em 2020 (GSMA, 2015).

O ecossistema da telefonia móvel é um dos principais motores do progresso da economia. Em 2014, a indústria da telefonia móvel gerou 3,8\% do PIB mundial (Produto Interno Bruto), uma contribuição de aproximadamente US\$ 3 trilhões em valores econômicos que atinge 236 países. Esta figura capta impactos diretos, indiretos e produtividade do ecossistema móvel, mas não incluem os efeitos socioeconômicos mais amplos. Em 2020, a contribuição do móvel na economia crescerá a uma taxa mais rápida do que o resto da economia global, contribuindo com 4,2\% para o PIB do mundo até o final do período (GSMA, 2015).

O ecossistema móvel empregou diretamente quase 13 milhões de pessoas em 2014, e aumentará para mais de 15 milhões até 2020. O setor também apoiou indiretamente quase 12 milhões de postos de trabalho na economia em geral em 2014, e há aumento previsto de mais de 13 milhões em 2020. A indústria também faz uma contribuição muito grande ao financiamento público por meio de tributações. Em 2014, aproximadamente contribuiu-se cerca de US\$ 410 bilhões a nível mundial com leilões de transmissão de sinais eletromagnéticos, criando uma receita adicional de mais de US\$ 14 bilhões (GSMA, 2015).

Para atingir plenamente o potencial total da telefonia móvel, populações ao redor do mundo precisam ter acesso a redes de telecomunicações, e poder adquirir dispositivos acessíveis e seus serviços. No final de 2014, o número de pessoas usando a internet móvel atingiu 2,4 bilhões. Este deverá subir para 3,8 bilhões em 2020, impulsionado pelo crescimento nos países em 
desenvolvimento. Atualmente, a concentração de populações "desconectadas" é predominantemente rural, com baixa renda e alto nível de analfabetismo, variáveis que são barreiras para utilização de Internet móvel. Operadores, e outros agentes do ecossistema, bem como os governos e reguladores, têm um papel a desempenhar na resolução dessas barreiras e melhorar o alcance e a acessibilidade dos serviços móveis (GSMA, 2015).

\subsection{Mercado de tecnologia de smartphone na China}

O interesse da China em modernizar a tecnologia de suas indústrias, levou a criação de programas nacionais de ciência e tecnologia, que possibilitaram o país a se tornar uma das potências tecnológicas no mundo (KASINSKI et al., 2011). Por meio desses incentivos, a China pode reforçar sua capacidade nacional e alcançou um desenvolvimento sustentável da sociedade. Foram criados parques tecnológicos, que possibilitariam a criação de setores de alta tecnologia. Afim de poder atingir outros âmbitos da sociedade, foram priorizadas as pesquisas inovadoras sobre agricultura, energia, meio ambiente, recursos naturais, entre outros (KASINSKI et al., 2011).

Considerado um dos programas de incentivo a empresas mais bem-sucedidos do mundo, o programa Torch, criado pelo governo chinês, foi responsável pela criação de grandes parques industriais de alta tecnologia, que oferecem várias políticas de incentivo que encorajam o investimento e formação de novas empresas (Hu, 2007).

Sendo considerado o maior mercado de smartphones do mundo, a China contava, em 2014, com 1,24 bilhões de assinantes (Reuters, 2014). E, as empresas chinesas como Huawei, Xiaomi e Lenovo despontam como maiores fabricantes do mundo, atrás apenas da Apple e Samsung (IDC, 2015). Essas empresas têm como diferencial a atuação no mercado de smartphones de baixo custo, e, a utilização da plataforma aberta Android, que providencia a maioria de seu código fonte de graça. Com a ajuda obtida pelo avanço da indústria tecnológica chinesa, conseguem todas peças para a construção do smartphone no próprio mercado chinês, resultando em baixo custo de produção (QIU, 2013).

\subsection{Breve histórico da empresa estudada}

Xiaomi é uma empresa Chinesa fundada em 2010 pelo empreendedor Lei Jun. A empresa produtora de dispositivos eletrônicos e de softwares, tornou-se a quinta maior distribuidora de smartphones do mundo, segundo índice IDC do último trimestre de 2014, com 16,6\% de participação no mercado. Lei Jun (ex-CEO da Kingsoft), formado em engenharia elétrica, tinha a ambição de elevar a qualidade do mercado de montagem de equipamentos da China a um nível de qualidade competitivo frente aos fabricantes internacionais. Após trabalhar por uma década em uma desenvolvedora de software, Jun decidiu entrar no ramo de smartphones. Com apoio de outros 6 engenheiros, e de empresas do seguimento de telecomunicação como a Qualcomm, e investimento 
de 41 milhões de dólares do próprio fundo e de outros fundos de investimento, a Xiaomi foi fundada no dia 6 de abril de 2010 na cidade de Pequim (AHMAD, 2015; CARVALHO, 2015; IDC, 2015; XIAOMI, 2015).

Inicialmente, focaram-se no desenvolvimento de software para sistema operacional Android, lançando em 2010, a MIUI, circuito integrado que permite customização extrema do sistema operacional Android. Posteriormente a empresa investiu seus esforços na criação de uma plataforma mensageiro semelhante ao Whatsapp, chamado de MiTalk. E em agosto de 2011 a empresou apresentou ao mercado o seu primeiro smartphone: o Mi-One, com valor aproximadamente de 325 Dólares e portando hardware de alta qualidade, o estoque rapidamente se esgotou. Seu sucesso foi resultado de uma soma de estratégia de corte de custos e da alta qualidade do produto. Ao dispensar a venda dos aparelhos por meio de distribuidores e vendedores, seu único canal de vendas é a ecommerce, o que permitiu uma economia em escala no custo de armazenagem e distribuição. Além da estratégia de precificação, a estratégia de marketing também se concentra na internet, tendo seu maior aliado de publicidade, as mídias sociais e a publicidade boca-a-boca dos seus consumidores. O relacionamento entre a empresa e os consumidores é um ponto forte, que permite feedback frequente, e consequentemente melhoria continua dos seus produtos e serviços de pós-venda. $\mathrm{O}$ ciclo de vendas dos seus produtos também é maior que os seus maiores concorrentes. Em geral, os grandes produtores de smartphones tem seus produtos a venda por um ciclo de 6 a 8 meses, e após esse período, cessam a produção e lançam uma nova linha de produtos. Enquanto os produtos da Xiaomi continuam a serem produzidos por um ciclo de 18 a 20 meses após o lançamento. Dessa forma é possível reduzir o custo em desenvolvimento de novos produtos (AHMAD, 2015; CARVALHO, 2015; KUMAR, 2014).

Após o domínio do mercado chinês, os executivos da Xiaomi decidiram internacionalizar a empresa, e para atingir com sucesso o objetivo, Hugo Barra, ex-diretor da divisão do sistema Android no Google fora contratado em 2013 para assumir a posição de vice-presidente global. Em 2014, a Xiaomi se consolidou em Hong Kong e Taiwan. E posterior em Cingapura, onde alcançaram resultados extraordinários, o estoque do celular Mi3 foi todo vendido em apenas dois minutos, fato que popularizou o nome da empresa pelo mundo. Em Malásia Filipinas e Índia, a empresa teve sucesso inicialmente, mas eventualmente sofreu ações judiciais. Para seguir com o objetivo de expansão global, a Xiaomi começou a mirar para ocidente, anunciando vendas na Rússia, México e Turquia. O resultado do plano de internacionalização tirou o posto de $14^{\circ}$ maior fabricante de celulares para o $3^{\circ}$ lugar em 2014, sendo o mercado chinês onde vem a maior parte da sua receita. A Xiaomi também está presente nos EUA e na Europa, porém somente com venda de acessórios como fones de ouvido, câmeras de ação, devido as questões legais a empresa ainda não 
consegue iniciar vendas de smartphones. As acusações enfrentadas são de plágio no quesito design dos celulares, por serem semelhantes aos produtos da Apple (CARVALHO, 2015).

Em 2015, a empresa em fase de rápida expansão, iniciou fabricação de outros seguimentos de produtos, como tablets, smart tvs, powerbanks e pulseira inteligente. E no segundo semestre de 2015 a Xiaomi iniciou suas vendas de smartphones e acessórios no Brasil. E para evitar das altas taxas de importação decidiram por fabricar os aparelhos no país em parceria com a Foxconn (CARVALHO, 2015).

No seu quadro de executivos e engenheiros compõe-se ex-funcionários proeminente de empresas como: Google, Kingsoft, Microsoft, Motorola, Yahoo, e de outras grandes corporações de tecnologia e internet. Atualmente o portfólio de hardwares da companhia consiste-se de: Mi4, Mi3, Mi Pad, Mi Box, Mi TV, Redmi 1S e Redmi Note, Mi Power Bank e outros acessórios (como fones de ouvido e pulseiras inteligentes) (AHMAD, 2015; CARVALHO, 2015; XIAOMI, 2015).

\subsection{Análise dos dados}

Abaixo são apresentados os dados coletados nas entrevistas realizadas com profissionais que atuam na área de marketing na Xiaomi no Brasil. O questionário aplicado era semiestruturado, visando obter o máximo de informações possíveis sobre a prática desse estilo de marketing no mercado brasileiro, averiguando se o uso dessa estratégia surtiria o mesmo efeito que o obtido na China, e a opinião da empresa sobre o conceito de Hunger Marketing e seus similares.

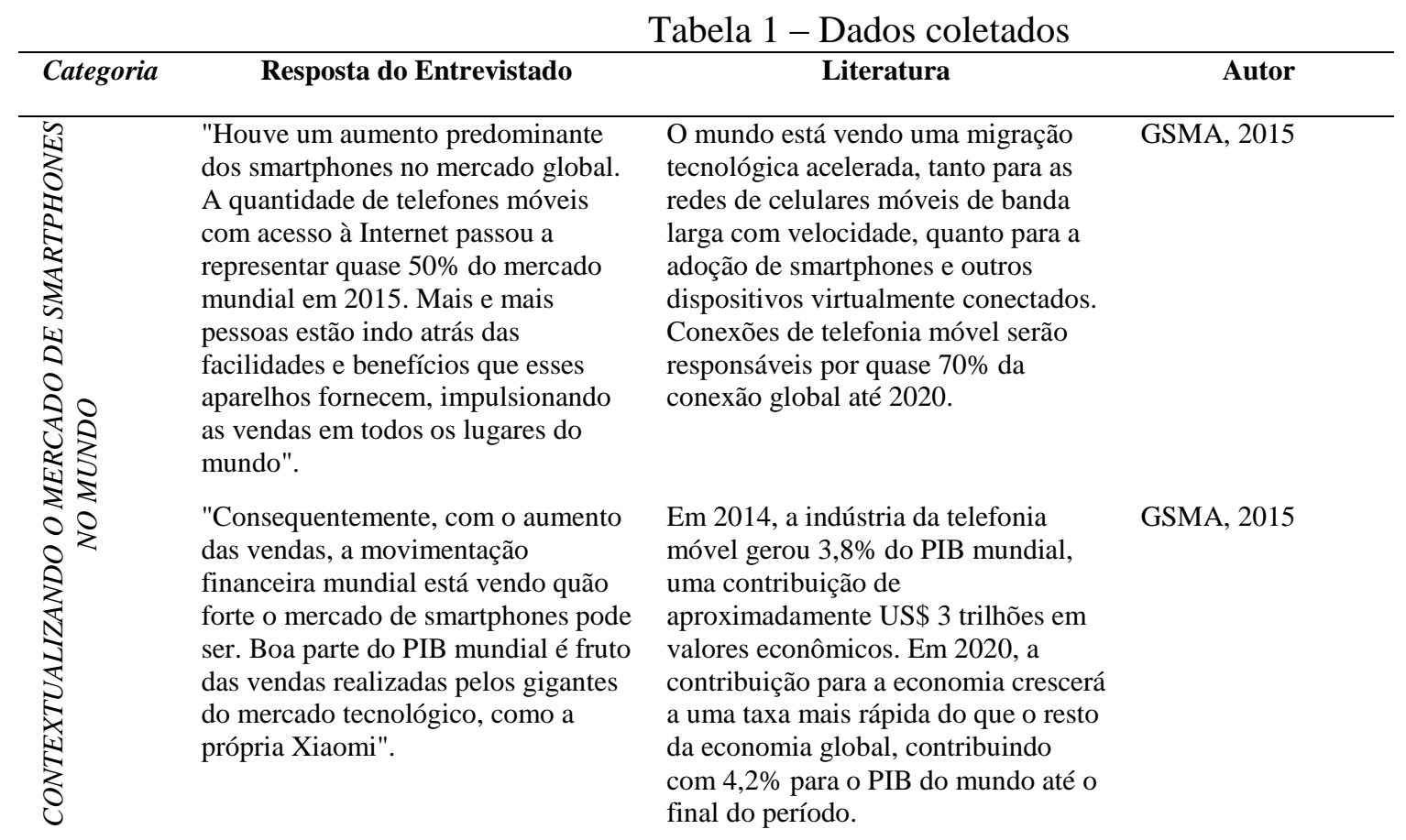


"A China é um dos maiores consumidores de tecnologia do mundo, além de ser um dos maiores mercados com potencial para fazer uma empresa desse ramo crescer. A Xiaomi surgiu com o intuito de satisfazer as necessidades apresentadas por esses consumidores tão exigentes e ansiosos por novidades".
Sendo considerado o maior mercado de smartphones do mundo, a China contava, em 2014, com 1,24 bilhões de assinantes. Os diferenciais da Xiaomi no mercado são o baixo custo e a utilização da plataforma aberta Android, que providencia a maioria de seu código fonte de graça. Com a ajuda obtida pelo avanço da indústria tecnológica chinesa, ela consegue todas peças para a construção do smartphone no próprio mercado chinês, resultando em baixo custo de produção.

"A Xiaomi é uma empresa que
surgiu com a intenção de mostrar ao
mundo que a China tinha potencial
para ser um país que ia além das
montagens de peças e equipamentos.

Seu sucesso foi resultado de uma soma de estratégia de corte de custos e da alta qualidade do produto. Ao dispensar a venda dos aparelhos por meio de distribuidores e vendedores, seu único canal de vendas é a ecommerce, o que permitiu uma economia em escala no custo de armazenagem e distribuição.
Reuters, 2014; Qiu, 2013

\author{
AHMAD, 2015; \\ CARVALHO \\ 2015; KUMAR, \\ 2014
}

\section{O termo Hunger Marketing (marketing de fome em português), é um tipo de estratégia que se utiliza de conhecimentos comportamentais para redirecionar a atenção do consumidor a aquisição de novos produtos.}

Pros

$\begin{array}{ll} & \text { "Isso faz com que a venda aumente } \\ \text { nos dando subsídio para nossos } \\ \text { próximos lançamentos. Isso não é }\end{array}$

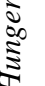

\begin{tabular}{|c|c|}
\hline 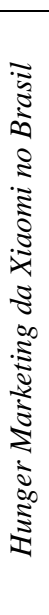 & $\begin{array}{l}\text { "Acredito que no Brasil ainda somos } \\
\text { muito tátil e somos levados por } \\
\text { "status" das grandes marcas. O } \\
\text { brasileiro quer ver antes, pegar e } \\
\text { saber o que o amigo do lado vai } \\
\text { achar se ele tiver aquele produto. O } \\
\text { brasileiro não liga apenas parar o que } \\
\text { tem de benefício no produto ele que } \\
\text { saber que valor aquele mesmo vai } \\
\text { agregar a sua vida. Acredito que com } \\
\text { a realidade da internet os grandes } \\
\text { labels vão ter que defender mais suas } \\
\text { bandeiras, mas isso custa caro, logo } \\
\text { as startups vão sucumbir com ideias } \\
\text { simples e diretas focadas no seu } \\
\text { nicho e a palavra Cliente vai ser } \\
\text { trocada por fã". }\end{array}$ \\
\hline
\end{tabular}
A empresa cria produtos para $o$ mercado com um preço atraente para atrair clientes potenciais e buscar ganhar espaço no mercado. A estratégia deve contar com uma marca de forte apelo. A Xiaomi usufrui das interações da mídia social online para torna a relação com seus consumidores mais próxima, além de permitir a cooperação dos usuários no desenvolvimento dos Softwares e

\author{
DRELL, 2011; \\ SCHMITT, 1999; \\ STONE; \\ SATARIANO; \\ TONESS, 2014 \\ SHEERAN, 2008; \\ GUPTA; \\ ISHNEET, 2014; \\ SHIH; LIN; \\ LUARN, 2014
}
YAN \& QU, 2014; Hardwares. O efeito final é de estabelecer uma imagem de marca de alto valor e com preço acessível.

$\begin{array}{ll}\text { Para a empresa chinesa, um de seus } & \text { SHIH; LIN; } \\ \text { valores essenciais é focar em seus fãs. } & \text { LUARN, } 2014 \\ \text { Portanto procura engajá-los com } & \\ \text { tópicos interessantes, respondendo } \\ \text { comentários, compartilhando ideias, } \\ \text { criando oportunidades para estreitar a } \\ \text { relação da empresa e seus } \\ \text { consumidores. }\end{array}$




\begin{tabular}{|c|c|c|c|}
\hline 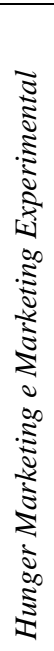 & $\begin{array}{l}\text { "Mkt Experencial é: tudo de } \\
\text { benefício que um produto pode ter. } \\
\text { Hunger Mkt: Pontuar onde e quando } \\
\text { seu produto se destaca". }\end{array}$ & $\begin{array}{l}\text { Com o surgimento da Economia das } \\
\text { Experiências, os consumidores } \\
\text { passaram a procurar por memórias } \\
\text { efetivas, por sensações, por } \\
\text { simbolismo, por aquilo que lhe } \\
\text { permitia criar uma experiência } \\
\text { pessoal única e memorável, além dos } \\
\text { benefícios visíveis dos produtos. O } \\
\text { Hunger Marketing avalia o mercado } \\
\text { para criar necessidade no cliente, } \\
\text { desenvolver um produto que ele } \\
\text { busca e mostrar como ele é melhor } \\
\text { que o do concorrente. }\end{array}$ & $\begin{array}{l}\text { PINE, GILMORE, } \\
\text { 1998; SCHMITT, } \\
\text { 2003; DRELL, } \\
\text { 2011; SCHMITT, } \\
\text { 1999; STONE; } \\
\text { SATARIANO; } \\
\text { TONESS, 2014; } \\
\text { YAN \& QU, } 2014\end{array}$ \\
\hline
\end{tabular}

Fonte: os autores 2016

Como observado ao decorrer das pesquisas realizadas, o smartphone tem impactado diferentes áreas das atividades humanas. As áreas de destaque, onde os impactos do smartphone são óbvios incluem negócios, educação, saúde e vida social. A tecnologia móvel mudou drasticamente as normas e comportamento dos indivíduos. Os impactos são positivos e negativos. Em uma extremidade os smartphones estão permitindo que as pessoas criem suas próprias microculturas e permitem que as elas permaneçam conectadas o tempo todo, por outro vemos que todos estão cada vez mais afastados da interatividade pessoal e mais dependentes dessa tecnologia.

A necessidade crescente e rápida do desenvolvimento da tecnologia na era da globalização dos mercados é cada vez mais feroz e a concorrência faz com que as empresas criem produtos para atender às diversas necessidades dos consumidores, especialmente na indústria de smartphones. Hoje em dia, o uso do smartphone tornou-se uma necessidade primária diária. Portanto, toda mudança na tecnologia deverá estar sempre em linha com as necessidades humanas.

O universo dos smartphones faz girar trilhões de dólares no mundo, contribuindo com uma parcela considerável do PIB mundial, e isso se dá devido ao crescente aumento nas vendas e na forma como as empresas fazem marketing. Portanto, adotar a estratégia correta e desenvolver os produtos conforme a real necessidade dos consumidores pode ser crucial para sobreviver no mercado de smartphones.

A Xiaomi foi fundada pelo empresário Lei Jun, e está criando a próxima onda na indústria de smartphone com o lançamento de celulares com Android inteligentemente desenvolvidos a custos muito moderados. Quando a empresa foi criada, em junho de 2010, abalou o mercado chinês em um período de 4 anos e está destinada a ser a próxima palavra da moda no mercado internacional.

A empresa tem uma estratégia "consumidor obcecado" onde ela permite que os clientes participem no seu processo de concepção e desenvolvimento por meio de seus fóruns on-line e incorporam seu feedback aos novos modelos/dispositivos. Um dos principais fatores de sucesso 
para Xiaomi na China (com exceção de dispositivos com recursos high end a custos acessíveis) é que eles conseguiram com sucesso envolver os consumidores no seu desenvolvimento de produtos e marketing. O modelo inovador de negócios da empresa não depende de hardware para impulsionar as receitas, e vende seus produtos principalmente através do seu site, onde a oferta é feita diretamente para o consumidor final para manter seus preços competitivos.

A estratégia de marketing da Xiaomi é o ponto focal deste estudo e um fator determinante para o sucesso de seus produtos. A estratégia de promoção primária da Xiaomi é o chamado "marketing de fome", que constitui essencialmente em colocar produtos no mercado com um valor atraente (ou preço) e, em seguida, restringir a oferta. Portanto, tem-se uma escassez imaginária que pode ganhar uma enorme força de mercado. Dessa forma a empresa desperta uma forte reação social e desenha a atenção dos consumidores, melhorando suas vendas. Para a empresa Xiaomi, o marketing boca a boca é extremamente importante para que a empresa tenha sucesso. Seus smartphones são produzidos, de forma que os clientes se sintam parte deste processo, sugerindo o que precisa ser melhorado. Além disso, valorizam muito as críticas a seus produtos, que são feitas, em sua maioria, por seus consumidores mais leais, já que poderão ter informações suficientes do que é preciso ser corrigido (SHIH; LIN; LUARN, 2014).

Contudo, é importante destacar a forte participação dos consumidores no processo de desenvolvimento dos novos produtos. Sem o envolvimento do seu grupo de fãs, a estratégia de 'hunger marketing' da Xiaomi não teria sucesso e o efeito de promoção não seria tão grande.

\section{Considerações Finais}

A realização desse estudo permitiu o aprofundamento do entendimento do conceito não pragmatizado na literatura acadêmica de marketing tradicional. Apesar de aparentar ser um termo relativamente novo e praticado por pouquíssimas empresas, pode-se notar que a ideia do "marketing de fome" surgiu a partir de um ramo do marketing já bem conhecido por todos: o marketing experiencial.

O marketing experiencial surgiu como uma forma das empresas obterem vantagem com relação aos seus concorrentes e obterem mais espaço no mercado. Enquanto o principal foco para o marketing tradicional era o produto e seus atributos e benefícios, o marketing experiencial muda esse foco e passa a ter o cliente como seu objetivo e traça suas metas para satisfazê-lo.

Essa vertente do marketing parte da mudança no comportamento do consumidor, que passa a buscar produtos que não apenas satisfaçam suas necessidades, mas que também possam criar sensações para eles. A partir desse novo estilo de tomar decisões do cliente, as empresas começaram a perceber que seria preciso mudar sua tática de vendas e seu objetivo para conseguir atender seus consumidores. 
Do entendimento do comportamento dos clientes, é possível para a empresa entender o perfil de compra dos mesmos e traçar suas estratégias a partir disso. Analisando as preferências e o que ele busca nos concorrentes, as empresas podem mudar seus produtos e adaptá-los para as preferências daqueles que os compram. Além disso, com o estudo do comportamento é possível gerar a necessidade no cliente, não apenas atende-las. Assim fica interessante ter claro como a experiência no processo de compra e a própria expectativa de compra afetam o mercado.

Com o surgimento dessa possibilidade, o horizonte de atuação das empresas passou a ser muito maior, visto que ela pode começar a despertar a necessidade no cliente a partir daquilo que ele procurava e com base naquilo que ela está oferecendo. Essa nova forma de entrar no mercado foi o marco inicial do Hunger Marketing, que surge a partir da criação de desejo nos consumidores.

A Xiaomi, principal empresa praticante dessa ramificação do marketing, trabalha com a criação de produtos que despertam a necessidade e o desejo de seus consumidores, que ficam ansiosos esperando pelos seus lançamentos. Praticamente a empresa faz uso das características biológicas dos serem humanos em ficarem em estado de expectativa constante quando vislumbrados pela possibilidade de um lançamento muito desejado. O sucesso pode ser notado pelo alto nível das vendas, que ocorrem apenas durante 24 horas de determinados dias (na China). Além dela, a Apple também segue a mesma ideia e trabalha em cima dos desejos de seus consumidores, aumentando-os com o anúncio do lançamento de determinados produtos.

Apesar do sucesso da empresa na utilização do Hunger Marketing no seu país de origem, não se pode dizer o mesmo do que está acontecendo no Brasil. Instalada há menos de um ano no país, a empresa chinesa não apresenta bons resultados quando comparados com sua performance na China, o que poderia causar uma possível saída do mercado brasileiro, visto que ele não tem se mostrado receptivo e empolgado. Aparentemente o que está acontecendo com a Xiaomi é fruto de uma estratégia de entrada não tão bem estruturada, o que culminou em péssimos resultados para a empresa. Dois fatores importantes que impactaram nesses resultados foram a escolha do produto para entrar no novo mercado e a definição do público alvo.

O aparelho Redmi 2 apresenta características inferiores ao Moto G $2^{\text {a }}$ Geração, produto mais vendido no mercado brasileiro quando eles vieram para cá, o que não agradou os first movers brasileiros, que esperavam um produto mais a altura da tecnologia apresentada pela Xiaomi, que teoricamente representaria a essência do hunger marketing preconizado pela empresa. Além da escolha do aparelho errado, houve também o equívoco na definição do público. A empresa chinesa optou por focar no público que compraria seu primeiro smartphone, ou seja, aqueles menos propensos a gastar seu dinheiro com uma marca não tão conhecida e que não apresentava um celular melhor do que o concorrente famoso e já conhecido do público, o que fez com que as vendas não alavancassem como o esperado. 
Outro erro cometido por eles foi não buscar parceria com as grandes lojas revendedoras de celulares, o que não permitia ao cliente a compra do aparelho sem ser pelo site oficial da empresa. Fato esse que acabou por desestimular o "apetite" dos clientes pelos produtos, que estão acostumados a encontrar smartphones em várias lojas, não apenas na loja ou site da marca do aparelho. Vendo as consequências disso, a Xiaomi logo tratou de firmar parcerias com essas lojas, mas o estrago estava feito e os consumidores praticamente haviam perdido o interesse, o que ocasionou um aumento indesejado dos estoques dos produtos.

Além desses sérios problemas desenvolvidos por conta de uma análise fraca e equivocada de inteligência de marketing, o uso do Hunger Marketing pela empresa no Brasil foi um fracasso. Ao tentarem colocar em prática a mesma estratégia que eles utilizam na China, ou seja, estabelecer um dia específico para realizar a venda dos produtos, foi verificado que os consumidores não ficaram satisfeitos, mas sim frustrados por não conseguirem adquirir o produto que queriam e terem que esperar por outra data. A Xiaomi deixou de analisar seu novo mercado para buscar entender se o uso desse tipo de marketing causaria os efeitos esperados ou contrários, que foi o que acabou acontecendo.

Portanto, concluímos que o termo Hunger Marketing não é totalmente novo, visto que ele também se baseia na busca por experiências e nas necessidades dos consumidores. A principal diferença dele para o marketing experiencial é que ele cria o desejo, enquanto o marketing experiencial busca atender esse desejo. Apesar disso, ambos têm como principal objetivo satisfazer o cliente e garantir a geração de emoções e satisfação. Também se nota que a utilização desse marketing pode não gerar os resultados esperados, visto que a empresa está lidando com uma variável não controlável que é o próprio consumidor. Trabalhar em cima das necessidades dos mesmos pode ser algo vantajoso e competitivo, mas deve-se tomar cuidado com relação as expectativas dos mesmos, já que para alguns esperar pelo produto ser vendido em determinados momentos pode ser prazeroso e interessante, enquanto que para outros pode gerar frustações e tormentos algo que limite a ação de compra.

\subsection{Limitações do trabalho}

A principal limitação apresentada nesse estudo foi com relação ao tema analisado. O termo Hunger Marketing não é muito conhecido no mercado ainda, portanto a quantidade de fontes disponíveis sobre ele era pouca, o que limitou o aprofundamento do tema. Além desse fator a metodologia escolhida também é limitada, visto que foi aplicada para uma empresa específica e seus resultados não podem ser usados para outras situações. 


\title{
7.2. Recomendações para futuros pesquisadores
}

Sugere-se para futuros pesquisadores que eles façam novamente o estudo na Xiaomi em um período diferente e daqui a alguns anos para analisar se a utilização do Hunger Marketing trouxe os benefícios esperados. Além disso, sugere-se também que eles estudem empresas que trabalhem com o marketing experiencial e analisem suas características para ver se elas o conceito de Hunger Marketing é algo efetivamente novo ou apenas um ramo do marketing experiencial.

\begin{abstract}
The present study is presented on the form of qualitative exploratory research. It is further complemented by a Hunger Marketing case study. For this, a research was carried out through the application of semi-structured questionnaires, aiming to understand a priori: how Hunger Marketing is at the service of mobile phone manufacturing companies. Finally, it is concluded that the term Hunger Marketing is not entirely new, since it is also based on the search for experiences and the needs of consumers. Its main difference to experiential marketing is that he creates desire, while experiential marketing seeks to fulfill that desire. Nevertheless, both have as main objective to satisfy the client and guarantee the generation of emotions and satisfaction. It is also noted that the use of this marketing may not generate the expected results, since the company is dealing with a non-controllable variable that is the consumer itself. Working needs can be advantageous and competitive, but care must be taken regarding expectations, since for some consumers to wait for the product can be pleasurable and interesting, while for others it can generate frustrations and torments something that limits the action of purchase.
\end{abstract}

Key Words: hunger marketing; smartphones; global market; China

\section{Referências}

AAKER, D. A.; MCLOUGHLIN, D. Strategic Market Management: Global Perspectives. John Wiley \& Sons, 2010. v. 8.

AHMAD, D. A brief history of Xiaomi - China's tech success story! Gizchina. Disponível em: http://www.gizchina.com/2014/04/18/brief-history-xiaomi-chinas-tech-success-story/. Acesso em: 19 de agosto de 2015.

BAINES, P.; FILL, C.; PAGE, K. Essentials of Marketing. [s.1.] OUP Oxford, 2013.

ARONNE, C. V.; VASCONCELOS, M.C.R.L., The Impact of Experiential Marketing on the Customer's Perception of a Brand's Essence. EnANPAD, 2009.

BRITO, C. P.; TOLEDO, G. L.; TOLEDO, L. A. Considerações sobre o conceito de marketing - teoria e prática gerencial. Revista organização \& sociedade, v. 50, n. jul-set, p. 519-543, 2009.

BROWN, S. L.; EISENHARDT, K. M. Competing on the Edge: Strategy as Structured Chaos: Harvard Business Press, 1998. 
CARvalHO, L. Conheça a História da Xiaomi. Xiaomi Brasil. Disponível em: http://xiaomibrasil.com/historia-daxiaomi/. Acesso em: 19 Ago. 2015.

CERVO, A; BERVIAN, P. Metodologia científica. 5. ed. São Paulo: Pearson Education, 2003.

COOPER, D.; SCHINDLER, P. S. Métodos de Pesquisa Em Administração. Bookman Companhia Ed, 2003.

DIÓGENES, E. Metodologia e Epistemologia na Produção Científica. UFAL, 2005.

DRELL, L. Inbound Marketing vs. Outbound Marketing. Disponível em: <http://mashable.com/2011/10/30/inbound-outbound-marketing/>. Acesso em maio de 2016.

DUFFY, D. L. Multi-channel marketing in the retail environment. Journal of Consumer Marketing, 2004. crossref

FERRELL, O. C.; HARTLINE, M. Marketing Strategy. [s.1.] Cengage Learning, 2012.

FIFIELD, P. Marketing Strategy. Routledge, 2012.

FOG, K.; BUDTZ, C.; YAKABOYLU, B. Storytelling: Branding in practice. [s.1.] Springer Berlin Heidelberg, 2005.

FROW, P. et al. Managing Co-creation Design: A Strategic Approach to Innovation. British Journal of Management, v. 26, n. 3, p. n/a-n/a, 22 fev. 2015.

GOBE, M. Emotional branding: the new paradigm for connecting brands to people. [s.l.] Allworth Press, 2001.

GOWER, B. Scientific Method: A Historical and Philosophical Introduction. Routledge, 2012.

GUPTA, S., \& ISHNEET, D. Creating global Shared Services. AIMA Journal of Management \& Research, 8(3/4), 67-72, 2014.

GUPTA, S.; HANSSENS, D.; HAUSER, J. R.; LEHMANN, D.; SCHMITT, B. Introduction to Theory and Practice in Marketing Conference Special Section of Marketing Science. Marketing Science, v. 33, n. 1, p. 1-5, 2014. INFORMS. cross ref

HERnANDEZ, J. M. DA C.; BASSO, K.; BRANDÃO, M. M. Pesquisa Experimental em Marketing. REMark Revista Brasileira de Marketing, v. 13, n. 2, p. 96-115, 2014.

HOOley, G. J.; PIERCY, N. F.; NICOUlAUd, B. Marketing Strategy and Competitive Positioning. 4th Edition. Pearson/Prentice Hall, 2008.

HOOLEY, G. J.; SAUNDERS, J. A.; PIERCY, N. F. Estratégia de marketing e posicionamento competitivo. [s.1.] Prentice Hall, 2001.

IDC. In a Near Tie, Apple Closes the Gap on Samsung in the Fourth Quarter as Wordwide Smartphone Shipments Top 1.3 Billion for 2014, According to IDC. Disponível em: <http://www.idc.com/getdoc.jsp?containerId=prUS25407215>. Acesso em: 25 de agosto, 2015.

KOTLER, P.; KARTAJAYA, H.; SETIAWAN, I. Marketing 3.0: From Products to Customers to the Human Spirit. [s.l.] John Wiley and Sons, 2011.

KOTLER, P.; KELLER, K. Marketing management: Analysis, planning, and control. Organization, 2009.

KOTLER, P.; PFOERTSCH, W. Ingredient Branding. [s.1: s.n.]. v. 57

KOtler, P., ARMStrong, G. Principles of Marketing - Fifth European Edition. England: Pearson Education, 2008 .

KUMAR, N. Marketing As Strategy: Understanding the CEO's Agenda for Driving Growth and Innovation. [s.l.] Harvard Business Press, 2013.

KUMAR. A. (2014) How Xiaomi sells its high-end phones at low prices: a short lesson in the Economics of Pricing. Disponível em: http://yourstory.com/2014/09/xiaomi-pricing-strategy-hugo-barra/ . Acesso em 15 de agosto, 2015. 
LAMBIN, J.-J. Marketing estratégico. McGraw-Hill, 2002

LIMEIRA, Tania Maria Vidigal. Comportamento do consumidor brasileiro. São Paulo: Saraiva, 2008.

MONTOYA, P. The personal branding phenomenon. [s.l: s.n.].

MORAES, A; TOLEDO, L. A. Estratégia Híbrida E Oligopólios: Um estudo da indústria do alumínio Hybrid Strategy and oligopolies: an aluminum industry Study. Gestão \& Regionalidade, v. 29, n. 86, p. 19-33, 2013. crossref

MORAL, M. M., ALLES, M. T. F. Nuevas tendencias del marketing: el marketing experiencial. Entelequia: revista interdisciplinar, n. 14, p. 237-251, 2012.

PETtigREW, A.; THOMAS, H.; WHITTINGTON, R. Handbook of Strategy and Management. Sage, 2002.

PIGGOTT, S. Snapshot review: Internet Strategy Handbook: Lessons from the New Frontier of BusinessBusiness Information Review, 1996.

PRATAS, C. I. C. Determinantes do Marketing Experiencial. Tese de Doutorado. Instituto Superior de Gestão, 2013.

RAJARATNAM, D.; CLARK, T. Handbook of Marketing (Book). Journal of Marketing, v. 67, n. 3, p. $129,2003$.

SANTO, A. DO E. Delineamentos de metodologia científica. Edições Loyola, 1992.

SARGI, L. P., MATTOS, A. O marketing de experiência e a sua importância no cenário mercadológico atual. Intercom: Campo Grande, MS, 2015.

SCHMITT, B. Experiential Marketing Journal of Marketing Management. 1999. crossref

SCHMITT, B.H. Customer experience management (CEM): a revolutionary approach to connecting with your customer. John Wiley and Sonc, Inc, Hoboken. New Jersey, 2003

SCHMITT, B. H. Experiential Marketing: how to get customers to sense, feel, think, act and relate to your company and brands. The Free Press, New York: 1999

SHEERAN, J. The challenge of hunger. The Lancet, v. 371, n. 9608, p. 180-181, 2008. crossref

SHETH, Jagdish N.; MITTAL, Banwari; NEWMAN, Bruce I. Comportamento do cliente: indo além do comportamento de do consumidor. São Paulo: Atlas, 2001.

SHIH, C.; LIN; T. M. Y; LUARN, P. (2014). Fan-centric social media: The Xiaomi phenomenon in China. Business Horizons, 57(3), 349-358, 2014. crossref

SKACEL, R. K. Plano de marketing. NBL Editora, 2005

SOLOMON, Michael R. O comportamento do consumidor: Comprando, possuindo e sendo. 9. ed.. Porto Alegre: Bookman, 2011.

STONE, B.; SATARIANO, A.; TONESS, B. V. Xiaomi Takes Direct Aim At the iPhone. Bloomberg Businessweek, n. 4388, p. 34-35, 2014.

TOLEDO, G. L. Relações públicas e marketing: um conceito tridimensional. EN-ANPAD, v. 18, p. p.145-15, 1994.

TOLEDO, L. A.; SHIRAISHI G.F. Estudo de caso em pesquisas exploratórias qualitativas: um ensaio para a proposta de protocolo do estudo de caso. Revista da FAE Curitiba, p. 103-119, 2009. Coritiba, Brasil.

Xiaomi, About Xiaomi. Disponível em: http://www.mi.com/en/about/ . Acesso em 19 de Agosto de 2015.

YAN, H; QU; X. (2014). Research on the Marketing Strategy of Luxury Goods. Contemporary Logistics, 15, 4247, 2014.

YIN, R. K. Applications of Case Study Research. SAGE Publications, 2012. 


\section{Dados dos autores:}

Nome completo: Luana Chen Chih Jun

Filiação institucional: Universidade Presbiteriana Mackenzie

Departamento: CCSA

Função ou cargo ocupado: Bacharel em Administração

Endereço completo para correspondência: Rua da Consolação 930, São Paulo, SP 01302-907 prédio 45

Telefone: (11) 2114-8000

e-mail: luanachen@gmail.com

Nome completo: Henrique Nishimoto

Filiação institucional: Universidade Presbiteriana Mackenzie

Departamento: CCSA

Função ou cargo ocupado: Bacharel em Administração

Endereço completo para correspondência: Rua da Consolação 930, São Paulo, SP 01302-907 prédio 45

Telefone: (11) 2114-8000

e-mail: Henrique @ gmail.com

Nome completo: Natália Correia Abreu

Filiação institucional: Universidade Presbiteriana Mackenzie

Departamento: CCSA

Função ou cargo ocupado: Bacharel em Administração

Endereço completo para correspondência: Rua da Consolação 930, São Paulo, SP 01302-907 prédio 45

Telefone: (11) 2114-8000

e-mail: Natália@gmail.com

Nome completo: Vivian Siqueira

Filiação institucional: Universidade Presbiteriana Mackenzie

Departamento: CCSA

Função ou cargo ocupado: Bacharel em Administração 
Endereço completo para correspondência: Rua da Consolação 930, São Paulo, SP 01302-907 prédio 45

Telefone: (11) 2114-8000

e-mail: vivian.damaceno10@gmail.com

Nome completo: Luciano Augusto Toledo

Filiação institucional: Universidade Presbiteriana Mackenzie

Departamento: CCSA

Função ou cargo ocupado: professor adjunto

Endereço completo para correspondência: Rua da Consolação 930, São Paulo, SP 01302-907 prédio 45

Telefone: (11) 2114-8000

E-mail: luciano.toledo@mackenzie.br

Submetido em: 25-05-2016

Aceito em: 21-09-2016 